\title{
Distribution characteristics of cow's milk-slgE components in children with respiratory allergic diseases in southern China
}

\author{
Huimin Huang ${ }^{\dagger}$, Wenting $\mathrm{Luo}^{\dagger}$, Nili Wei, Xueqing Liang, Peiyan Zheng, Haisheng Hü and Baoqing Sun ${ }^{*}$ (D)
}

\begin{abstract}
Background: Cow's milk (CM) is the main food allergen for toddlers and infants. Presently, studies on CM specific immunoglobulin E (slgE) sensitization and positive distribution of CM components ALA-, CAS-, and BLG-slgE are lacking in infants with respiratory allergic diseases, especially in southern China. This study therefore aimed to investigate the distribution of CM sensitization and the relation between its components a-lactalbumin (ALA), $\beta$-lactoglobulin (BLG) and casein (CAS) slgE in children with respiratory allergic diseases in southern China.

Methods: A total of 1839 children ( $\leq 12$ years) with respiratory diseases and detected CM-slgE levels were included. Serum samples were collected from the Respiratory Diseases Bioresources Center of the National Center for Respiratory Diseases in southern China from August 2012 to July 2017. ALA-, BLG-, and CAS-slgE were detected and questionnaires were completed in 103 children.

Results: A total of $36.7 \%$ children were positive for CM-slgE. CM-slgE levels were higher in asthmatic bronchitis (AB) group than in other allergic respiratory disease groups (all $P<0.05$ ). Among the $103 \mathrm{CM}$-slgE-sensitized children, $64.08 \%$ had a history of family allergies. There were $84.47 \%$ of the children who tested positive for two or more slgE components. The average ALA-, BLG-, and CAS-slgE levels were $1.91 \mathrm{kU} / \mathrm{L}, 1.81 \mathrm{kU} / \mathrm{L}$, and $0.62 \mathrm{kU} / \mathrm{L}$, respectively. The CM-slgE level showed a correlation with BLG-slgE $\left(r_{s}=0.833\right)$, ALA-slgE $\left(r_{s}=0.816\right)$, and CAS-slgE $\left(r_{s}=0.573\right)$ levels (all $p<0.001)$.

Conclusions: In southern China, CM-slgE levels were higher in children with $A B$ than in those with other respiratory allergic diseases. ALA and BLG were the main allergenic components detected in CM-slgE-sensitized children with respiratory allergic diseases.
\end{abstract}

Keywords: Respiratory allergic diseases, Cow's milk, Component, Specific immunoglobulin E

\section{Highlights}

- $36.7 \%$ of the children positive for CM-sIgE in southern China

- The positive rare of CM-sIgE levels were higher for asthmatic bronchitis $48.7 \%$ than for braochial asthma (34.5\%), cough variant asthma (34.4\%), combined allergic rhinitis and asthma syndrome (30.3\%) and allergic rhinitis (29.1\%).

- The positive rare of ALA-, BLG-, and CAS-sIgE were $87.4,86.4$ and $69.9 \%$ in children respectively, which was the first study in southern China.

\footnotetext{
* Correspondence: 781640613@qq.com; sunbaoqing@vip.163.com †Huimin Huang and Wenting Luo contributed equally to this work. Department of Allergy and Clinical Immunology, National Clinical Research Center of Respiratory Disease, State Key Laboratory of Respiratory Disease, Guangzhou Institute of Respiratory Health, The First Affiliated Hospital of Guangzhou Medical University, 151 Yanjiangxi Road, Guangzhou 510120, Guangdong, China

\section{Background}

Globally, the prevalence of food allergies in children is estimated to be $4-7 \%$ [1]. Cow's milk (CM) is one of the most common foods allergen for infants and young children. With the increasing pace of modern life, 
decreasing rate of breast-feeding, and increasing dependence on formula milk powder, the problem of $\mathrm{CM}$ allergy (CMA) has become a serious health concern. In Europe, the prevalence of CMA is above 3\% [2], while in America, it is $1.8 \%$ among children within $1-7$ years of age [3]. In southern China, the rate of self-reported CMA among children aged 1-7 years is 1.9\% [4].

Atopy is a risk factor for childhood asthma [5, 6], and our recent research based on real world data shows that there are $28.1 \%$ childhood asthma patients who are positive for $\mathrm{CM}$ allergen [7]. This may be because sensitization to $\mathrm{CM}$ allergens increases the risk of early respiratory allergic diseases in children $[8,9]$. Component-resolved diagnostics (CRD) holds promise for improving diagnostic accuracy and has recently been introduced into routine clinical practice [10]. Therefore, early detection of CM SIgE antibodies and analysis of the distribution of CM component sIgE in children with CMA and respiratory allergies are necessary.

The leading components of $\mathrm{CM}$ allergen are casein (CAS), $\alpha$-lactalbumin (ALA) and $\beta$-lactoglobulin (BLG) [11]. CAS accounts for $80 \%$ of the CM components and is found in four forms: $\alpha$-casein, $\beta$-casein, $\gamma$-casein, and $\kappa$-casein. Whey protein accounts for $20 \%$ of the CM components and is found as ALA, BLG, bovine serum albumin (Bos D 6), immunoglobulin (Bos D 7) and lactoferrin [12].

Currently, studies on CM sIgE sensitization and positive distribution of CM components ALA-, CAS-, and BLG-sIgE are lacking in infants with different kinds of respiratory allergic diseases, especially in southern China, where there is a large number of potential children with respiratory allergic diseases. According to the survey by Professor Li J [13, 14], the prevalence of physician-diagnosed asthma in children was $6.9 \%$, and that of self-reported allergic rhinitis was $23.2 \%$ in southern China (Guangzhou). Thus, the purpose of this study was to investigate sensitization to CM-sIgE and its components (ALA-, BLG-, and CAS-sIgE), as well as to update the spectrum of biological indicators in children with respiratory allergic diseases in southern China.

\section{Methods}

\section{Ethical considerations}

The study was approved by the Ethics Committee of the First Affiliated Hospital of Guangzhou Medical University (Ethical code: GYFYY-2016-73). Serum samples were collected from the Respiratory Diseases Bioresources Center of the National Center for Respiratory Diseases in southern China. All patients had signed the formal written informed consent before their biological samples were entered into the biological resource database. The Ethics Committee of the First Affiliated Hospital of Guangzhou Medical University approved that when using the biological samples from the Respiratory Diseases Bioresources Center of the National Center for Respiratory Diseases, it was only necessary to inform the patients or the parents/guardians of the patients orally. In this study, oral consent was obtained from parents/ guardians of the children to participate after they had filled the questionnaires, and then detected serum ALA-, BLG-, and CAS-sIgE of the children.

\section{Study subjects and questionnaire survey}

This wasa prospective study. Children's serum samples were collected from the Bioresource Bank of the $\mathrm{Na}$ tional Center for Clinical Research of Respiratory Diseases from August 2012 to July 2017. We selected 1839 children who met the following criteria: (1) aged $\leq 12$ years; (2) had respiratory allergic disease(s) (diagnosed by respiratory specialists or pediatricians) including bronchial asthma (BA), allergic rhinitis (AR), combined allergic rhinitis and asthma syndrome (CARAS), cough variant asthma (CVA), and asthmatic bronchitis ( $\mathrm{AB})$; and (3) were suspected of CMA with CM-sIgE detected. Children with parasitic infection, immune deficiency and other immune diseases were eliminated.

Among them, serum ALA-, BLG-, and CAS-sIgE were detected in a total of $103 \mathrm{CM}$-sensitized children who completed questionnaires by phone in this study. The questionnaire was answered by parents, and questions included age, gender, birth season, clinical diagnosis, family history and other details (Table 1). All the questionnaires were screened strictly based on what we needed to study and ensure the quality of the questionnaire (Additional file 1). Before data entry, we checked and re-checked the original data to remove incomplete or vague questionnaire. Data entry adopted two-way entry method. The researcher who administered the telephone questionnaires also entered the questionnaire information, and this was checked by another researcher.

\section{Detection of slgE for $\mathrm{CM}$ and its components}

The ImmunoCAP system (Thermo Fisher Scientific, Sweden) was used to detect CM-, ALA-, BLG-, and CAS-sIgE. The detection range for sIgE was 0.00-100.00 $\mathrm{kU} / \mathrm{L}$. SIgE-positivity was categorized into 6 classes: class $1(\geq 0.35$ to $<0.70 \mathrm{kU} / \mathrm{L})$, class $2(\geq 0.70$ to $<3.50 \mathrm{kU} / \mathrm{L})$, class $3(\geq 3.50$ to $<17.50 \mathrm{kU} / \mathrm{L})$, class $4(\geq 17.50$ to $<50.00 \mathrm{kU} / \mathrm{L})$, class $5(\geq 50.00$ to $<100.00 \mathrm{kU} / \mathrm{L})$, and class $6(\geq 100.00 \mathrm{kU} / \mathrm{L})$. Children with sIgE levels $\geq 0.35 \mathrm{kU} / \mathrm{L}$ (class 1 or above) were defined as positive cases.

\section{Statistical analyses}

All data were processed using SPSS 19.0 (SPSS, Chicago, IL). Non-parametric quantitative data were presented as medians (with interquartile ranges). The Mann-Whitney 
Table 1 Baseline characteristics of 103 CM-slgE-sensitized children in the study

\begin{tabular}{|c|c|c|c|c|c|c|c|c|}
\hline Characteristic & $N$ & $\begin{array}{l}\text { Percentage } \\
(\%)\end{array}$ & $\begin{array}{l}\text { Positivity rate of ALA-slgE } \\
\text { (\%) }\end{array}$ & $P$ & $\begin{array}{l}\text { Positivity rate of BLG-slgE } \\
(\%)\end{array}$ & $P$ & $\begin{array}{l}\text { Positivity rate of CAS-slgE } \\
(\%)\end{array}$ & $P$ \\
\hline \multicolumn{9}{|l|}{ Sex } \\
\hline M & 74 & 71.84 & 87.84 & 1.000 & 83.78 & 0.339 & 68.92 & 0.728 \\
\hline F & 29 & 28.16 & 86.21 & & 93.1 & & 72.41 & \\
\hline \multicolumn{9}{|l|}{ Birth season } \\
\hline $\begin{array}{l}\text { Spr and } \\
\text { Sum }\end{array}$ & 42 & 40.78 & 95.24 & 0.069 & 92.86 & 0.875 & 69.05 & 1.000 \\
\hline Aut and Win & 61 & 59.22 & 81.97 & & 81.97 & & 70.49 & \\
\hline \multicolumn{9}{|l|}{ Age group } \\
\hline $0-2$ years & 30 & 29.13 & 80.00 & 0.396 & 96.67 & 0.081 & 73.33 & 0.207 \\
\hline $2-3$ years & 37 & 35.92 & 89.19 & & 86.49 & & 59.46 & \\
\hline$\geq 3$ years & 36 & 34.95 & 91.67 & & 77.78 & & 77.78 & \\
\hline \multicolumn{9}{|l|}{ Clinical diagnosis } \\
\hline$A B$ & 45 & 43.69 & 91.11 & 0.381 & 93.33 & 0.087 & 66.67 & 0.528 \\
\hline Non-AB & 58 & 56.31 & 84.48 & & 81.03 & & 72.41 & \\
\hline \multicolumn{9}{|c|}{ Family allergy history } \\
\hline No history & 37 & 35.92 & 86.49 & 0.822 & 94.59 & 0.197 & 70.27 & 0.918 \\
\hline Both parents & 20 & 19.42 & 95.00 & & 80.00 & & 70.00 & \\
\hline Only father & 19 & 18.45 & 84.21 & & 73.68 & & 63.16 & \\
\hline Only mother & 18 & 17.48 & 83.33 & & 88.89 & & 77.78 & \\
\hline Others & 9 & 8.74 & 88.89 & & 88.89 & & 66.67 & \\
\hline \multicolumn{9}{|c|}{ Duration of breastfeeding } \\
\hline$<6$ months & 62 & 60.19 & 83.87 & 0.236 & 82.26 & 0.154 & 72.58 & 0.466 \\
\hline$>6$ months & 41 & 39.81 & 92.68 & & 92.68 & & 65.85 & \\
\hline
\end{tabular}

Spr Spring, Sum Summer, Aut Autumn, Win Winter, $A B$ asthmatic bronchitis, Non-AB non-asthmatic bronchitis

test was used as a non-parametric test while the Chisquare test was used for comparison of positivity rates between two groups. Spearman analysis was used for evaluating the levels of sIgE antibodies. $P$ values $<0.05$ were considered statistically significant.

\section{Results}

\section{CM-slgE sensitization in children with respiratory allergic diseases}

The median age of the children included in the study was $4.0(2.0-6.0)$ years. There were $36.7 \%$ cases of CMsIgE positivity, and the average level of CM-sIgE among the CM-sensitized children was $1.00(0.56-2.00) \mathrm{kU} / \mathrm{L}$. Among the 1256 males, the CM-sIgE positivity rate was $36.9 \%$, and the average level of CM-sIgE among CMsensitized males was $1.04(0.58-2.16) \mathrm{kU} / \mathrm{L}$. On the other hand, among 583 females, the CM-sIgE positivity rate was $36.2 \%$, and the average level of CM-sIgE among the CM-sensitized females was $0.90(0.54-0.64) \mathrm{kU} / \mathrm{L}$. There were no statistical differences in CM-sIgE levels and positivity rates between the two genders $(P>0.05)$.

\section{Distribution of serum CM-slgE in children with different respiratory allergic diseases}

The serum CM-sIgE positivity rates in children with different respiratory allergic diseases, from high to low, were: $48.7 \%$ in $\mathrm{AB}$ group, $34.5 \%$ in $\mathrm{BA}$ group, $34.4 \%$ in CVA group, $30.3 \%$ in CARAS group, and $29.1 \%$ in AR group. The distribution of CM-sIgE in children with different respiratory allergic diseases was shown in Fig. 1. The proportion of children with class $3 \mathrm{CM}$-sIgE levels was highest in the $\mathrm{AB}$ group (8.6\%), followed by the $\mathrm{BA}$ group (4.0\%), and the AR group (1.0\%). Figure 2 shows the distribution of CM-sIgE levels in children with different respiratory allergic diseases. The CM-sIgE level in the $A B$ group was higher than that in the other respiratory allergic disease groups (all $P<0.05$ ).

Relationship between age and serum CM-slgE levels in children with different respiratory allergic diseases

Negative correlation was found between age and CMsIgE levels in the 1839 children with respiratory allergic diseases $\left(r_{s}=-0.346, p<0.001\right)$ in this study. The serum 


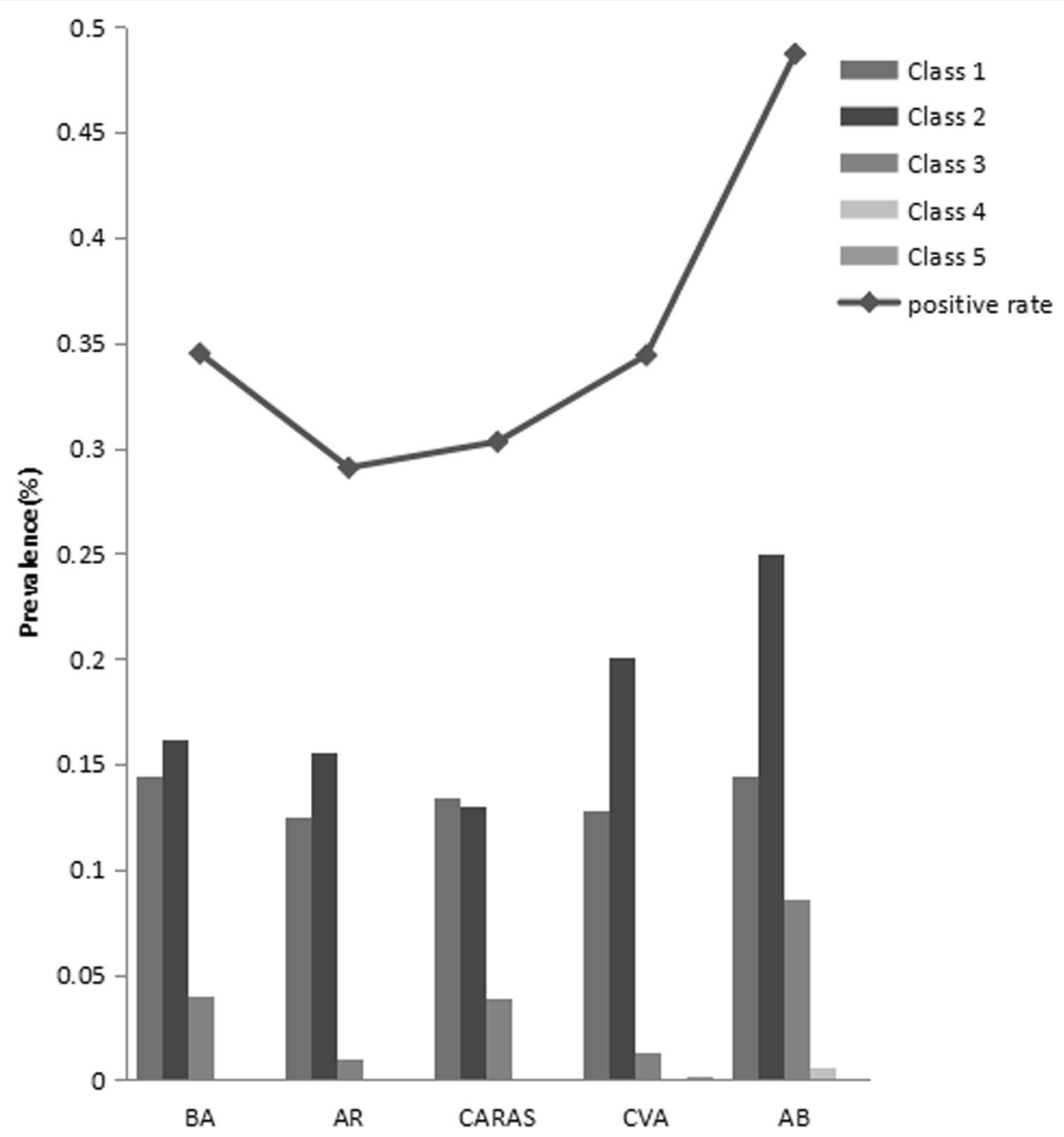

Fig. 1 Distribution of CM-slgE levels in children with different respiratory allergic diseases. For bronchial asthma (BA), there were 403 cases; allergic rhinitis (AR), 296 cases; combined allergic rhinitis and asthma syndrome (CARAS), 208 cases; cough variant asthma (CVA), 468 cases; asthmatic bronchitis (AB), 464 cases

CM-sIgE levels showed negative correlation with age in the BA group $\left(r_{s}=-0.325, P<0.001\right)$, AR group $\left(r_{s}=-0.379, P<0.001\right)$, CARAS group $\left(r_{s}=-0.446\right.$, $P<0.001)$, and CVA group $\left(r_{s}=-0.385, P<0.001\right)$, but not in the $\mathrm{AB}$ group.

\section{Distribution characteristics of serum CM components in children with respiratory allergic diseases}

The questionnaire was completed for 103 children in whom CM components were detected. The median age of the children was $2.0(1.4-3.0)$ years, and the average CM-sIgE level was $3.40(1.46-5.75) \mathrm{kU} / \mathrm{L}$. The basic clinical data for all the children were summarized in Table 1.

A family history of allergies was noted in $64.08 \%$ of the children. The ALA-sIgE positivity rate was higher in children who were born in Spring and Summer compared to those born in Autumn and Winter $(P=0.069)$. The BLG-sIgE positivity rate in the AB group was higher than that in the non-AB group $(P=0.087)$. The positivity rate of BLG-sIgE showed a negative correlation with age $(P=0.081)$. However, the above differences were not reach statistically significant.

Among the 103 children, the positivity rate was 87.38\% for ALA-sIgE, $86.41 \%$ for BLG-sIgE, and 69.90\% for CAS-sIgE. Positivity for not less than two and for three sIgE components was seen in 84.47 and $59.22 \%$ of the cases, respectively (Fig. 3). Based on the detected CM-sIgE levels, most of the cases belonged to class 2 and 3 (class 1, 6.80\%; class 2, 45.63\%; class 3, 40.78\%; class 4, 4.85\%; and class 5,1.94\%). ALA-sIgE and BLGsIgE levels accounted for the highest proportions in classes 2 and 3 (class 2, 40.78 and $42.72 \%$, respectively; and class 3, 34.95 and $33.01 \%$ respectively), followed by CAS-sIgE levels in class 1 (23.30\%) and class 2 (37.86\%). While CM-sIgE levels reached class 5, ALA- and BLGsIgE levels were class 3 , and CAS-sIgE levels were class 4. (Fig. 4a). 


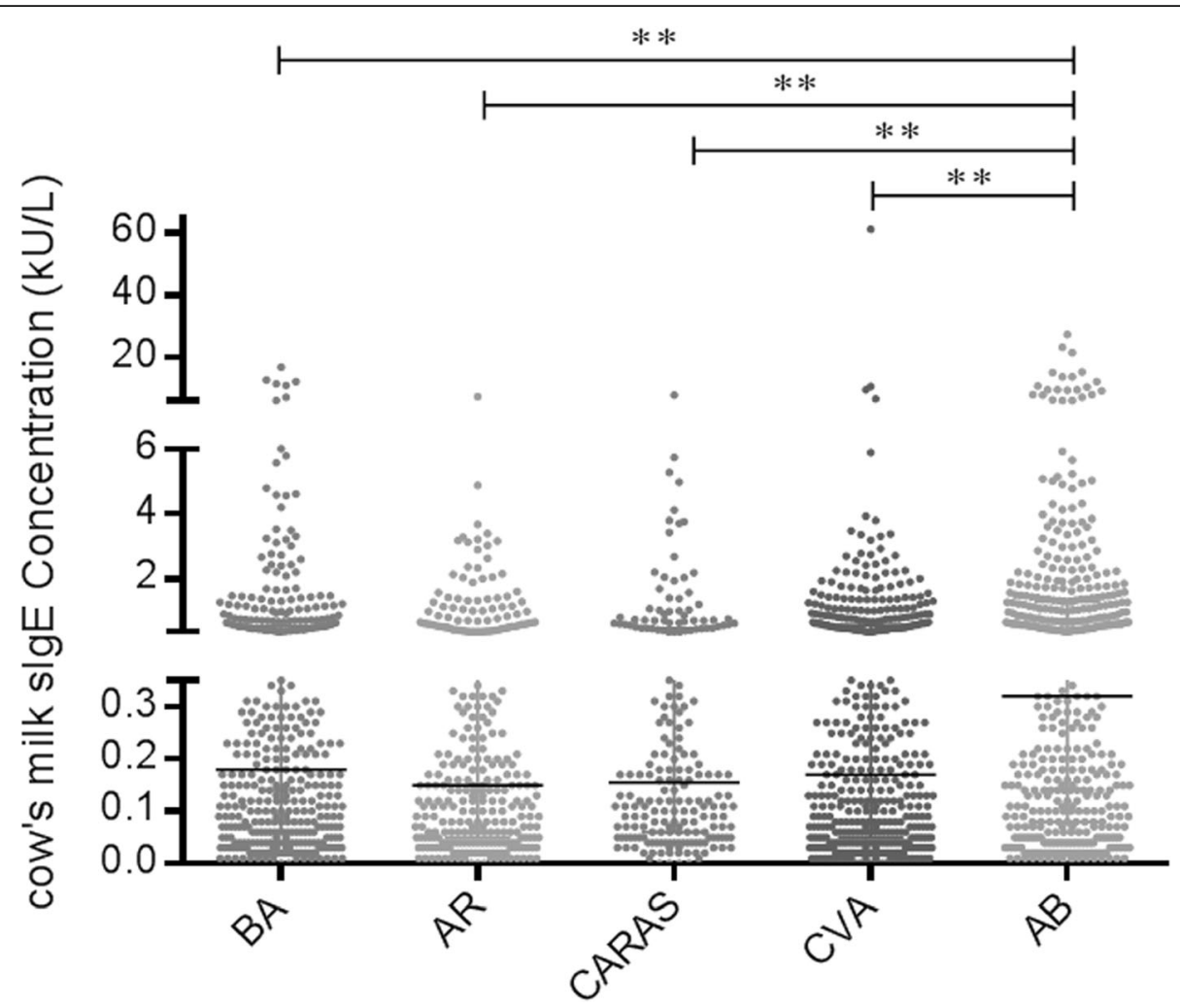

Fig. 2 Distribution of the serum level of CM-slgE in children with different respiratory allergic diseases. Based on the Mann-Whitney test, bronchial asthma (BA), 403 cases; allergic rhinitis (AR), 296 cases; combined allergic rhinitis and asthma syndrome (CARAS), 208 cases; cough variant asthma (CVA), 468 cases; asthmatic bronchitis (AB), 464 cases

The average ALA-, BLG-, and CAS-sIgE levels in CMsIgE-sensitized children were $1.91(0.66-5.24) \mathrm{kU} / \mathrm{L}$, $1.81(0.77-4.19) \mathrm{kU} / \mathrm{L}$, and $0.62(0.27-1.32) \mathrm{kU} / \mathrm{L}$, respectively. CM-sIgE levels were higher than ALA-sIgE $(z=-2.439, P=0.015)$, BLG-sIgE $(z=-3.228, P=0.001)$, and CAS-sIgE $(z=-8.726, P<0.001)$ levels. ALA-sIgE and BLG-sIgE levels were higher than CAS-sIgE levels $(z=-5.720, P<0.001$ and $z=-5.582, P<0.001$, respectively) (Fig. 4b).

\section{Correlation between levels of CM-, ALA-, BLG-, and CAS-slgE}

With an increase in CM-sIgE levels, the levels of each $\mathrm{CM}$ components showed an increasing trend (Fig. 5). Based on the Spearman correlation analysis, the correlation between CM-sIgE and BLG-sIgE was the highest, while that between CM-sIgE and CAS-sIgE was the lowest. Among the three $\mathrm{CM}$ components, the correlation between ALA-sIgE and BLG-sIgE was the highest, followed by that between BLG-sIgE and CAS-sIgE, while it was lowest between ALA-sIgE and CAS-sIgE.

\section{Discussion}

Children with infantile food allergy (FA) tend to develop asthma and allergic rhinitis later in life, and this is referred to as the "allergic march" [15]. Studies have shown that children with FA are at an increased risk of developing asthma and decreased lung functions [1618]. CM is a major cause of food allergies in infants and toddlers and may be related to the occurrence and development of respiratory allergic diseases. This study investigated the positive distribution of CM-sIgE and its components in children with respiratory allergic diseases and found a positivity rate of $36.7 \%$. The positivity rates for ALA-, BLG-, and CAS-sIgE in the CM-sIgEsensitized children were $87.38,86.41$, and $69.90 \%$, respectively. Tomac et al. [19] reported that early allergen sensitization in infants, especially CMA, was the most important risk factor for subsequent wheezing attacks. In this study, CM-sIgE levels in children with $A B$ were higher than those in children with other respiratory allergic diseases. Lopez et al. [20] have reported that the CM-sIgE level in 12-month-old infants with recurrent wheezing was higher than that in non-wheezing infants. Therefore, clinicians need to pay attention to CMA in children with $\mathrm{AB}$.

In this study, most of the CM-sensitized children reacted to two or more $\mathrm{CM}$ components at the same time, which was consistent with the results of D'Urbano et al. [21]. In Taiwan, ALA was shown to be the major 


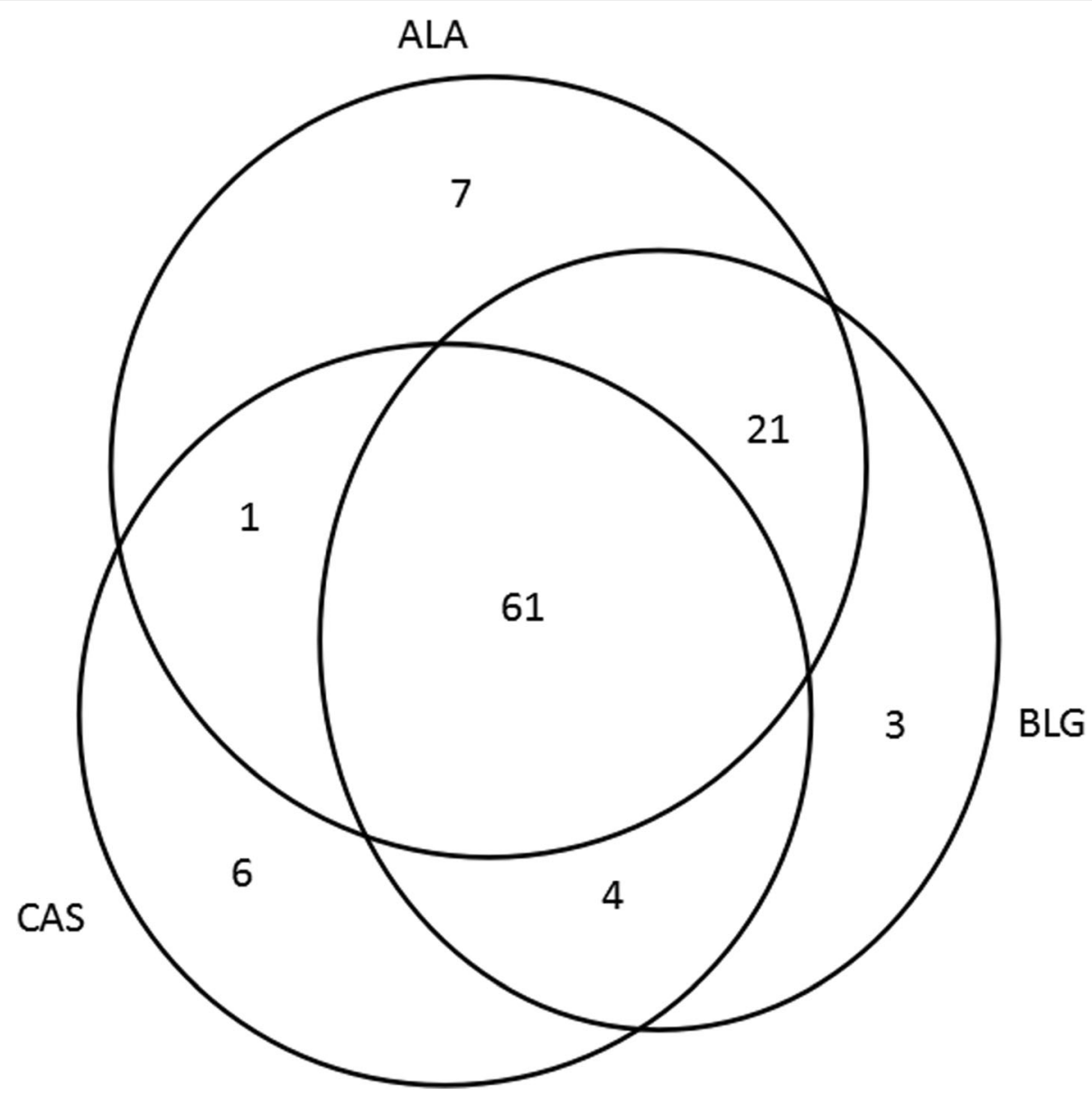

Fig. 3 Distribution of cases of sensitization to each CM component. ALA: a-lactalbumin; BLG: $\beta$-lactoglobulin; CAS: casein

sensitizing component in CM-sensitized children with allergic diseases [22]. However, in this study, from southern China, the major sensitizing components were found to be ALA and BLG, with ALA-sIgE and BLGsIgE levels being higher than CAS-sIgE levels. This difference in the prevalence of CM components may be due to the different types of diseases in the patients [23], thereby indicating different patterns of CM protein sensitization in different diagnoses of CMA. In different regions, dietary structure of children's milk sensitization model is different. According to $\mathrm{Li} \mathrm{J}$ et al. [24], the positivity rate of CAS-sIgE was higher than that of ALA-sIgE and BLG-sIgE in children with CMA in northern China.

The positivity rate of CM-sIgE has also been found to decrease with age. Rona et al. [25] have reported that the incidence of self-reported milk allergies is $6-7 \%$ in children and $1-2 \%$ in adults. More than $50 \%$ of children with CMA will become CM tolerant by 5 years of age [26]. With the increase in age, the positivity rate for BLG-sIgE declined, though there were no significant differences among the different age groups probably due to the sample size, suggesting that BLG-sIgE may be the main component of CM-sIgE that decreases with age.

We found that the level of three components CM-sIgE increased with an increase in levels of CM-sIgE. ALAand BLG-sIgE levels were highly correlated with CMsIgE levels. Though the CM components of sIgE cannot be used as diagnostic indices of CMA, higher ALA-, BLG-, and CAS-sIgE levels are associated with lower success rate of oral immunotherapy [27], which suggests that the distribution of sIgE could predict the outcomes of CMA.

Although most children could tolerate $\mathrm{CM}$ as they grew older, some others had CMA that persisted for their whole lives. The positivity rates and levels of CASsIgE were lower than those of ALA-sIgE and BLG-sIgE. However, the recognition of casein fragments by IgE is related to persistent CMA [28-30], and casein is more heat-resistant than whey protein. Allergy to baked milk powder has also been found to be a marker of severe and persistent CMA [31]. Therefore, the level of CAS-sIgE could be a predictor of the type and severity of CMA. 

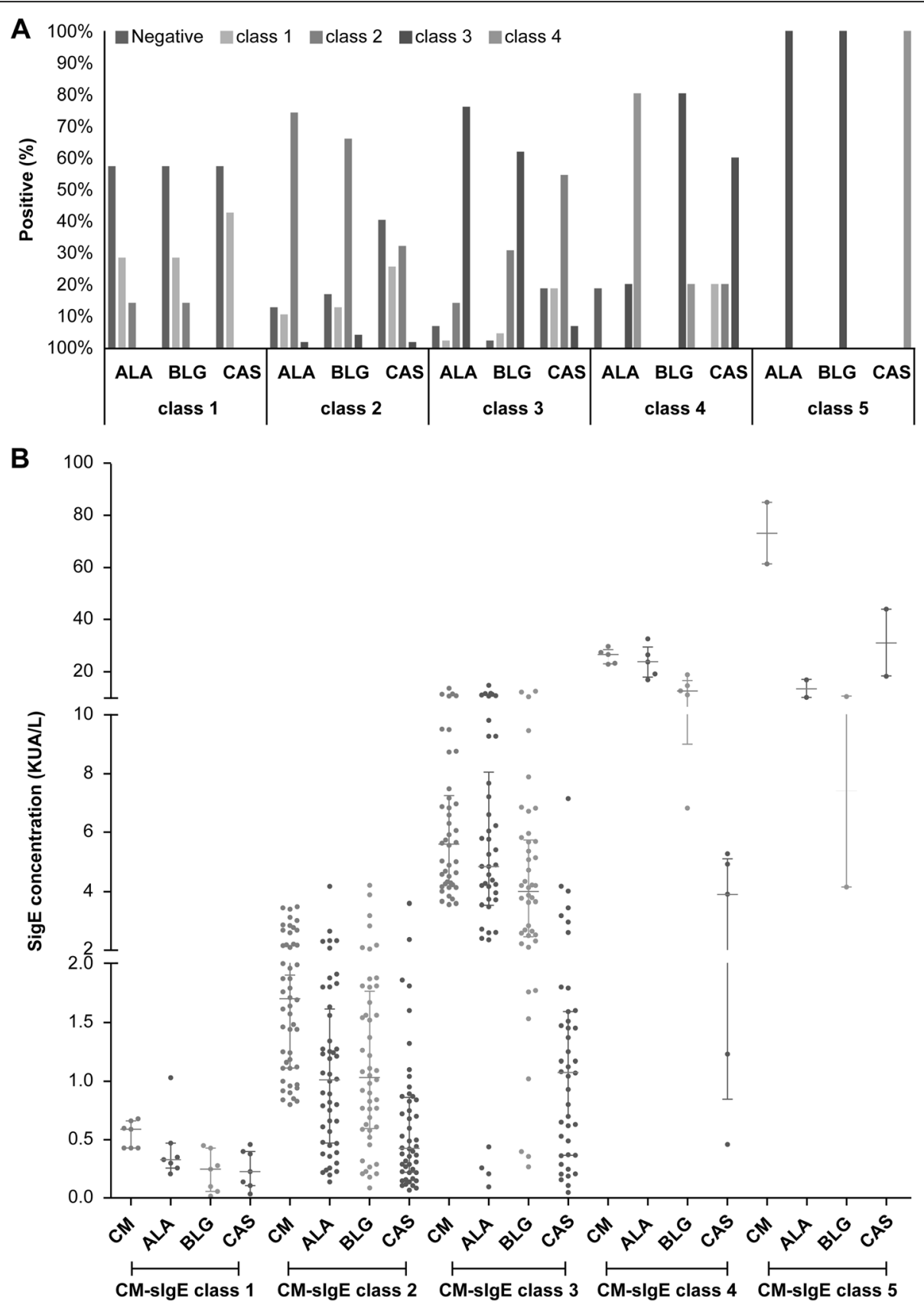

Fig. 4 Class and level distribution of the three components of slgE at different CM-slgE levels. a Class distribution of the three components of slgE in the different CM-slgE classes, and $\mathbf{b}$ Level distribution of ALA-, BLG-, and CAS-slgE in the different CM-slgE classes

Matsui $\mathrm{T}$ et al. [32] showed that food sensitization was related to season of birth, and a study showed that infants born in Autumn and Winter were more likely to develop food allergies [33]. In this study, ALA-sIgE positivity rate was higher in children who were born in Spring and Summer compared to those born in Autumn and Winter, but the difference was not statistically significant. It may be related to the differences of population and research indicators.
According to our survey, there was no statistical difference in the positivity rates of ALA-, BLG-, and CASsIgE of CM-sIgE-sensitized children between those who were breastfed for more than 6 months and those who were breastfed for less than 6 months. Although some studies had shown that breastfeeding could reduce the risk of milk allergy in infants [34, 35]. Rajani PS et al. [36] showed that the food antigens in human milk can elicit clinical reactions in some, already-sensitized 


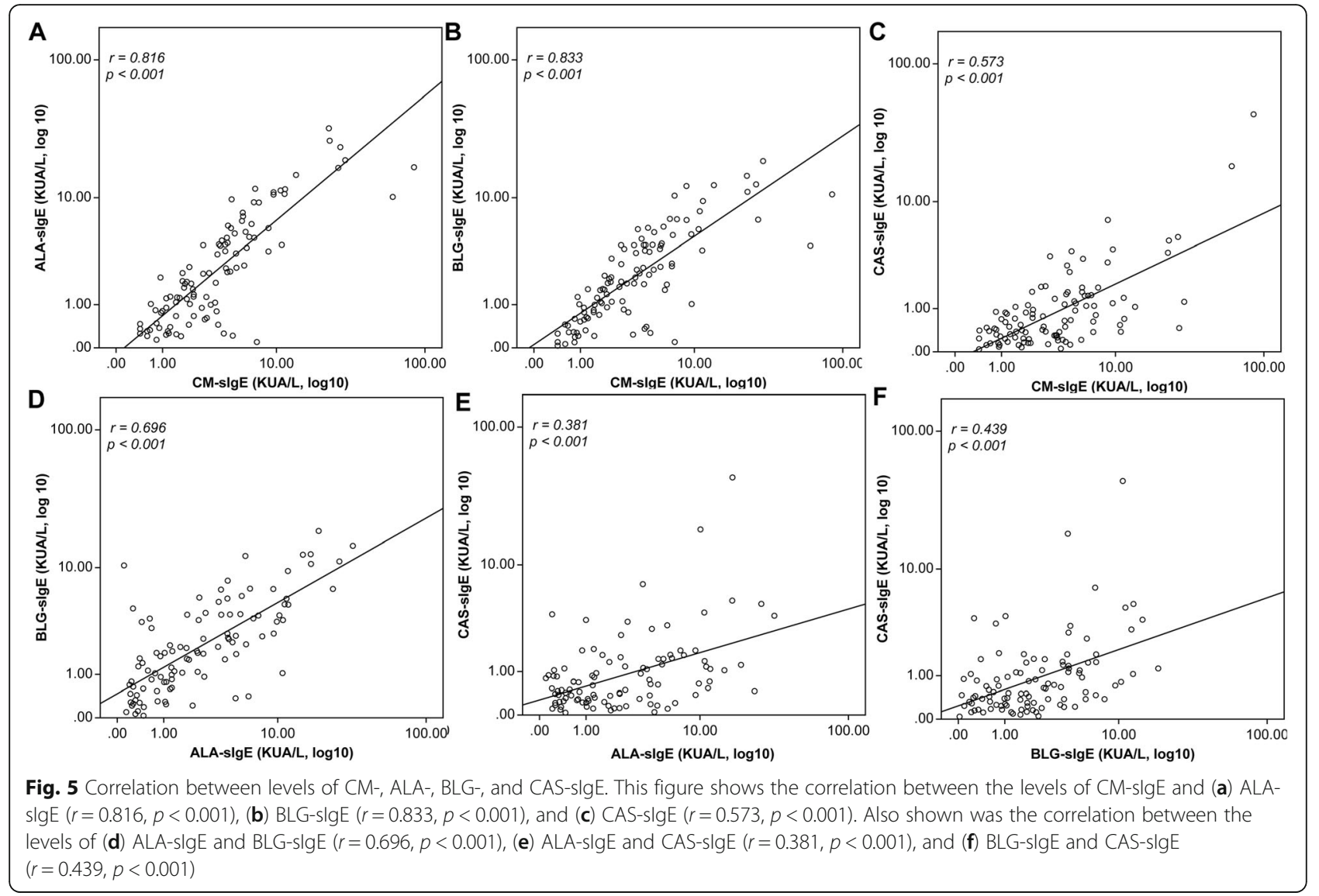

infants. Therefore, mother's eating habits will affect the development of food sensitization of breast fed infants.

$\mathrm{CM}$ sensitization should not be ignored in children with respiratory allergic diseases, especially in those with $A B$. Clinicians should pay special attention to children with $\mathrm{AB}$ and reconsider treatment strategies based on the patient's symptoms and the history of food intake.

The main limitation of this study was it only detected three CM components SIgE, but failed to analysis the antibody levels of other $\mathrm{CM}$ components, the other $\mathrm{CM}$ components maybe also a factors causing respiratory diseases in children, which we can't ignore. The children in this study were from the respiratory diseases Bioresources center of the National Center for Respiratory Diseases in southern China. All the selected children with respiratory allergic diseases, so we did not included the control group. And the sample size of this study needs to be increased. In addition, we will add longitudinal cohort studies in the future, and to assess the "allergic march" in food allergic children with respiratory diseases.

\section{Conclusion}

This is the first study that explored the positive distribution characteristics of CM-sIgE and its components, including ALA-, BLG-, and CAS-sIgE in children with respiratory allergic diseases in southern China. CM-sIgE levels in children with $A B$ were higher than those in children with other respiratory allergic diseases. ALA and BLG were the main allergenic components detected in CM-sIgE-sensitized children with respiratory allergic diseases.

\section{Supplementary information}

Supplementary information accompanies this paper at https://doi.org/10. 1186/s12887-020-1971-z.

Additional file 1. Questionnaire.

\section{Abbreviations}

AB: Asthmatic bronchitis; ALA: a-lactalbumin; AR: Allergic rhinitis; Aut: Autumn; BA: Bronchial asthma; BLG: $\beta$-lactoglobulin; CARAS: Combined allergic rhinitis and asthma syndrome; CAS: Casein; CM: Cow's milk; CMA: Cow's milk allergy; CVA: Cough variant asthma; FA: Food allergy; slgE: Specific immunoglobulin E; Spr: Spring; Sum: Summer; Win: Winter

\section{Acknowledgements}

We thank everyone involved in the collection, storage, transportation, and management of the serum samples.

\section{Authors' contributions}

B.Q.S was the group leader. B.Q.S and H.S.H conceived and designed the experiments. H.M.H and W.T.L wrote the main manuscript text and

performed data analysis. N.L.W and X.Q.L performed the measurements. P.Y.Z 
interpreted the experimental data. The author(s) read and approved the final manuscript.

\section{Funding}

This study was supported by Medical Science and Technology Research Foundation of Guangdong (Project No.: A2019224), Cultivation Project of the First Affiliated Hospital of Guangzhou Medical University (Project No.: ZH201818),Guangzhou Education Bureau (Project No.: 1201630393;

1201630044), and National Natural Science Foundation of China (Project No.: 81871736, 81802076, 81601394)

\section{Availability of data and materials}

The data that support these findings are available on reasonable request from the corresponding author Baoqing Sun. Data are not publicly available due to concerns regarding research participant privacy.

\section{Ethics approval and consent to participate}

The study was approved by the Ethics Committee of the First Affiliated Hospital of Guangzhou Medical University (Ethical code: GYFYY-2016-73). Serum samples were collected from the Respiratory Diseases Bioresources Center of the National Center for Respiratory Diseases in southern China. Al patients had signed the formal written informed consent before their biological samples were entered into the biological resource database. The Ethics Committee of the First Affiliated Hospital of Guangzhou Medical University approved that when using the biological samples from the Respiratory Diseases Bioresources Center of the National Center for Respiratory Diseases, it was only necessary to inform the patients or the parents/guardians of the patients orally. In this study, oral consent was obtained from parents/guardians of the children to participate after they had filled the questionnaires, and then detected serum ALA-, BLG-, and CAS-slgE of the children.

\section{Consent for publication}

Not applicable.

\section{Competing interests}

The authors declare that they have no competing interests.

Received: 9 September 2019 Accepted: 11 February 2020

\section{Published online: 24 February 2020}

\section{References}

1. Sicherer SH, Sampson HA. Food allergy: epidemiology, pathogenesis, diagnosis, and treatment. J Allergy Clin Immunol. 2014;133:291-307.

2. Nwaru BI, Hickstein L, Panesar SS, Roberts G, Muraro A, Sheikh A. Prevalence of common food allergies in Europe: a systematic review and meta-analysis. Allergy. 2014;69:992-1007.

3. Liu AH, Jaramillo R, Sicherer SH, Wood RA, Bock SA, Burks AW, et al. National prevalence and risk factors for food allergy and relationship to asthma: results from the National health and nutrition examination survey 20052006. J Allergy Clin Immunol. 2010;126:798-806.

4. Zeng GQ, Luo JY, Huang HM, Zheng PY, Luo WT, Wei NL, et al. Food allergy and related risk factors in 2540 preschool children: an epidemiological survey in Guangdong Province, southern China. World J Pediatr. 2015:11:219-25

5. Malmberg LP, Saarinen KM, Pelkonen AS, Savilahti E, Mäkelä MJ. Cow's milk allergy as a predictor of bronchial hyperresponsiveness and airway inflammation at school age. Clin Exp Allergy. 2010;40:1491-7.

6. Sarria EE, Mattiello R, Yao W, Chakr V, Tiller CJ, Kisling J, et al. Atopy, cytokine production, and airway reactivity as predictors of pre-school asthma and airway responsiveness. Pediatr Pulmonol. 2014:49:132-9.

7. Sun $\mathrm{BQ}$, Chen DH, Zheng PY, Huang HM, Luo WT, Zeng GQ, et al. Allergyrelated evidences in relation to serum IgE: data from the China state key laboratory of respiratory disease, 2008-2013. Biomed Environ Sci. 2014;27: 495-505. https://doi.org/10.3967/bes2014.081.

8. Ciprandi G, Sivestri M. Serum specific IgE: a biomarker of response to allergen immunotherapy. J Investig Allergol Clin Immunol. 2014;24:35-9.

9. Tosca M, Silvestri M, Accogli A, Rossi GACG. Serum-specific lgE and allergen immunotherapy in allergic children. Immunotherapy. 2014;6:29-33.

10. Borres MP, Maruyama N, Sato S, Ebisawa M. Recent advances in component resolved diagnosis in food allergy. Allergol Int. 2016;65:378-87.
11. Restani P, Ballabio C, Di Lorenzo C, Tripodi S, Fiocchi A. Molecular aspects of milk allergens and their role in clinical events. Anal Bioanal Chem. 2009;395:47-56.

12. Wal JM. Bovine milk allergenicity. Ann Allergy Asthma Immunol. 2004:93:S2-11.

13. Feng M, Yang Z, Pan L, Lai X, Xian M, Huang X, et al. Associations of early life exposures and environmental factors with asthma among children in rural and urban areas of Guangdong, China. Chest. 2016;149:1030-41.

14. Yang Z, Zheng W, Yung E, Zhong N, Wong GWK, Li J. Frequency of food group consumption and risk of allergic disease and sensitization in schoolchildren in urban and rural China. Clin Exp Allergy. 2015;45:1823-32.

15. Sohi DK, Warner JO. Understanding allergy. Paediatr Child Health (Oxford). 2008:18:301-8.

16. Hoyos-Bachiloglu R, Ivanovic-Zuvic D, Álvarez J, Linn K, Thöne N, de los Ángeles Paul M, et al. Prevalence of parent-reported immediate hypersensitivity food allergy in Chilean school-aged children. Allergol Immunopathol. 2014:42:527-32.

17. Friedlander JL, Sheehan WJ, Baxi SN, Kopel LS, Gaffin JM, Ozonoff A, et al. Food allergy and increased asthma morbidity in a school-based Inner-City asthma study. J Allergy Clin Immunol Pract. 2013;1:479-84.

18. Schroeder A, Kumar R, Pongracic JA, Sullivan CL, Caruso DM, Costello J, et al. Food allergy is associated with an increased risk of asthma. Clin Exp Allergy. 2009;39:261-70.

19. Tomac N, Turan E, Ertan U, Ozmen S. Cow's milk allergy as a risk factor for forthcoming wheezing attacks. Allergy Eur J Allergy Clin Immunol. 2004:59:1017-8

20. Lopez N, de Barros-Mazon S, Marluce dos Santos Vilela M, Condino Neto A, Ribeiro JD. Are immunoglobulin E levels associated with early wheezing? A prospective study in Brazilian infants. Eur Respir J. 2002;20:640-5.

21. D'Urbano LE, Pellegrino K, Artesani MC, Donnanno S, Luciano R, Riccardi C, et al. Performance of a component-based allergen-microarray in the diagnosis of cow's milk and hen's egg allergy. Clin Exp Allergy. 2010;40: 1561-70.

22. Chen FM, Lee JH, Yang YH, Lin YT, Wang LC, Yu HH, et al. Analysis of alactalbumin-, $\beta$-lactoglobulin-, and casein-specific IgE among children with atopic diseases in a tertiary medical center in northern Taiwan. J Microbiol Immunol Infect. 2014;47:130-6.

23. Jessadapakorn W, Sangsupawanich P, Wootipoom N, Suddeaugrai O, Yuenyongviwat A. Component-resolved diagnostics in thai children with cow's milk and egg allergy. Asian Pacific J Allergy Immunol. 2017;35:179-85.

24. Li J, Zhang J, Qiong C, She T, Bian Y, Lin S, et al. Component resolved diagnostic study of cow's milk allergy in infants and young children in northern China. Int Immunopharmacol. 2018;61:126-31.

25. Rona RJ, Keil T, Summers C, Gislason D, Zuidmeer L, Sodergren E, et al. The prevalence of food allergy: a meta-analysis. J Allergy Clin Immunol. 2007;120:638-46.

26. Wood RA, Sicherer SH, Vickery BP, Jones SM, Liu AH, Fleischer DM Henning AK, Mayer L, Burks AW, Grishin A, Stablein DSH. The natural history of milk allergy in an observational cohort. J Allergy Clin Immunol. 2013;131:805-12.

27. Kuitunen $M$, Englund $H$, Remes $S$, Movérare $R$, Pelkonen A, Borres MPMM High lgE levels to a-lactalbumin, $\beta$-lactoglobulin and casein predict less successful cow's milk oral immunotherapy. Allergy. 2015;70:955-62.

28. Vila L, Beyer K, Järvinen KM, Chatchatee P, Bardina L, Sampson HA. Role of conformational and linear epitopes in the achievement of tolerance in cow's milk allergy. Clin Exp Allergy. 2001;31:1599-606.

29. Cerecedo I, Zamora J, Shreffler WG, Lin J, Bardina L, Dieguez MC, et al. Mapping of the $\lg E$ and $\lg G 4$ sequential epitopes of milk allergens with a peptide microarray-based immunoassay. J Allergy Clin Immunol. 2008:122:589-94.

30. Járvinen KM, Beyer K, Vila L, Chatchatee P, Busse PJ, Sampson HA. B-cell epitopes as a screening instrument for persistent cow's milk allergy. J Allergy Clin Immunol. 2002;110:293-7.

31. Kim JS, Nowak-Wgrzyn A, Sicherer SH, Noone S, Moshier EL, Sampson HA. Dietary baked milk accelerates the resolution of cow's milk allergy in children. J Allergy Clin Immunol. 2011;128:125-31.

32. Matsui T, Tanaka K, Nakagawa T, Sasaki K, Nakata J, Sugiura S, et al. Sun exposure inversely related to food sensitization during infancy. Pediatr Allergy Immunol. 2015;26:628-33.

33. Vassallo MF, Banerji A, Rudders SA, Clark S, Camargo CA. Season of birth and food-induced anaphylaxis in Boston. Allergy. 2010;65:1492-3. 
34. Muraro A, Dreborg S, Halken S, Host A, Niggemann B, Aalberse R, et al. Dietary prevention of allergic diseases in infants and small children. Part III: critical review of published peer-reviewed observational and interventional studies and final recommendations. Pediatr Allergy Immunol. 2004;15:291-307.

35. Liao SL, Lai SH, Yeh KW, Huang YL, Yao TC, Tsai MH, et al. Exclusive breastfeeding is associated with reduced cow's milk sensitization in early childhood. Pediatr Allergy Immunol. 2014;25:456-61.

36. Rajani PS, Martin H, Groetch M, Järvinen KM. Presentation and Management of Food Allergy in Breastfed Infants and Risks of Maternal Elimination Diets. J Allergy Clin Immunol Pr. 2019;\$2213-2198:30943-2.

\section{Publisher's Note}

Springer Nature remains neutral with regard to jurisdictional claims in published maps and institutional affiliations.

Ready to submit your research? Choose BMC and benefit from:

- fast, convenient online submission

- thorough peer review by experienced researchers in your field

- rapid publication on acceptance

- support for research data, including large and complex data types

- gold Open Access which fosters wider collaboration and increased citations

- maximum visibility for your research: over $100 \mathrm{M}$ website views per year

At $\mathrm{BMC}$, research is always in progress.

Learn more biomedcentral.com/submissions 